\title{
Erratum to: Recent advances in capsule- based dry powder inhaler technology
}

Federico Lavorini ${ }^{i^{*}}$, Massimo Pistolesi ${ }^{1}$ and Omar S. Usmani ${ }^{2}$

\section{Erratum}

After publication of the article [1] it was brought to our attention that resistance values of Breezahler $(0.15 \mathrm{cmH} 2 \mathrm{O} /$ $\mathrm{L} / \mathrm{min})$ and Handihaler $(0.22 \mathrm{cmH} 2 \mathrm{O} / \mathrm{L} / \mathrm{min})$ are incorrect. (page 4 right column, lines 14 and 16 from below). The correct resistance values of Breezhaler and Handihaler are 0.07 and $0.16 \mathrm{cmH} 2 \mathrm{O} / \mathrm{L} \cdot \mathrm{min}^{-1}$, respectively. We apologise for the inaccuracy.

\section{Author details}

${ }^{1}$ Department of Experimental and Clinical Medicine, Careggi University Hospital, Florence, Italy. ${ }^{2}$ National Heart and Lung Institute, Imperial College London\& Royal Brompton Hospital, London, UK.

Received: 14 June 2017 Accepted: 16 June 2017

Published online: 23 June 2017

\section{Reference}

1. Lavorini F, Pistolesi M, Usmani OS. Recent advances in capsule-based dry powder inhaler technology. Multidiscip Respir Med. 2017;12:11. doi:10.1186/ s40248-017-0092-5.

\footnotetext{
*Correspondence: federico.lavorini@unifi.it

'Department of Experimental and Clinical Medicine, Careggi University Hospital, Florence, Italy
} 